\title{
Development of high school students' geometric thinking with particular emphasis on mathematically talented students
}

\author{
ÁKOs GYŐRY AND EsZTER KÓNYA
}

\begin{abstract}
We carried out research using Zalman Usiskin's test (1982) and also a modified version of his test to see how the geometric approach of secondary school students (Grades 8-10) specialized in mathematics had changed. We observed two groups of students for several years. Our aim was to find a relation between the change of the mean of the van Hiele level of the students and the structure of the geometry syllabus. We also observed if there was a change in the geometric approach of the students during the summer holidays and if so, in what way it changed.
\end{abstract}

Key words and phrases: Van Hiele theory, Levels of geometric thinking, Structure of the geometry syllabus, Summer holiday.

ZDM Subject Classification: D63, G13.

\section{Introduction}

From the mid-1980s several studies have been written about learning and teaching geometry (Cwowley, 1987; Gutierrez, Jaime \& Fortuny, 1991; Mason, 1997). The reason for this is that while learning geometry students face a number of difficulties. The research has shown that the main reason for the poor performance of students in geometry lies in school teaching (Gutierrez, Jaime \& Fortuny, 1991; Halat, 2006-2007). The first author's own experiences fully correspond to these results. Currently, he is a high school math teacher in Hungary and deals with students specialized in mathematics. Although his students 
are mathematically talented students and they have 6-8 mathematics (including geometry) lessons per week, the author has experienced most of the problems mentioned in the previous studies while these students solved geometry tasks. For this reason it is of crucial importance to examine the development of talented students' geometric thinking, to familiarize the results with the teachers and to integrate them into the teaching process.

\section{Theoretical background}

The van Hiele theory, one of the most respected theories describing geometric thinking, was started to develop by two Dutch educators Dina van Hiele-Geldof and her husband, Pierre van Hiele in the 1950s when studying their students. Based on their observations they analyzed and described the process of developing geometric thinking. The essence of the theory is that the development of the geometric approach is divided into levels from the global recognition of the shapes to the writing a formal geometric proof (Usiskin, 1982). The levels are sequential and hierarchical, reaching a given level assumes access to all previous levels. Each level has its own mathematical language and the successful teaching process requires that the teacher communicates with the students at an appropriate level but not in the language of a higher level. According to the theory, the development of geometric thinking is divided into 5 levels, although later studies emphasize several times that the fifth level cannot be measured.

Level 1 (Visualization or recognition). At this stage of development students recognize and name the individual geometric shapes, but treat them as single entities. At this time they do not yet perceive the components and properties of the shapes. In addition to being able to separate the shapes from each other, they do not yet see any connection between them. For example, they recognize rectangles based on their shape, but the square is not classified among them. Students rely on perceptions when reasoning.

Level 2 (Analysis). At this level students already separate the components of shapes from each other and from the whole. They perceive the different attributes of individual shapes and can already group them. However, they are not yet able to link the various properties of a particular shape or the properties of different shapes. Students are capable neither to form definition, nor to formulate cause and effect relationships. At this level they do not rank squares among 
rectangles, but for example, they know that all sides of a rhombus have equal lengths.

Level 3 (Abstraction). At this level the students are already systematize the attributes, and can link the shapes to each other by their properties. They see relationships between attributes (for example in a triangle there is larger angle opposite to larger side), and students are able to understand the hierarchy of geometric concepts. At this point, students are, for example, classifying squares consciously into rectangles. At this level they understand the exact definitions and are able to formulate cause-and-effect relationships and to follow a chain of conclusions.

Level 4 (Deduction). At this stage students really understand the meaning of deduction. They can differentiate between definition, theorem, proposition, lemma and corollary. They already have the need for proof of their statements. At this time they are able to formulate conclusions in the learned Euclidean axioms system independently and to construct simple proofs. They already know and use different techniques of proof (e.g. indirect proof, mathematical induction), they are aware of the importance of axioms and non-defined concepts. They understand what the necessary and sufficient terms as concepts mean. They are not yet able to provide full axiomatic proof, and while proving they believe in statements that need to be proven.

Level 5 (Rigor). At this level students can understand and deduct formal conclusions without the use of specific geometric interpretations. Students can formulate conclusions not only in the Euclidean axiomatic system, but also they draw a parallel between systems based on different axioms.

To justify the van Hiele theory, a number of studies were carried out in the 1980s (Usiskin, 1982; Mayberry, 1983; Fuys, Geddes and Tischler, 1988; Burger and Shaughnessy, 1986). There is a consensus among researchers that van Hiele levels characterize the state of development of geometric thinking well. The only controversial question is the assessment of Level 5, many researchers think that this level cannot be measured exactly or it does not exist at all (Usiskin, 1982; Haviger and Vojkůvková, 2014). Several tools have been developed to measure the van Hiele levels (Usiskin, 1982; Mayberry, 1983), but these studies do not investigate the thinking of highly talented students in mathematics, which is our goal. 


\section{Mathematics education for highly talented students in Hungary}

In Hungary since 1962 there has been a special mathematics education program for highly talented students. ${ }^{1}$ Currently there are 11 grammar schools with one or two classes in each of them, where mathematics is taught according to this program, four are in Budapest, and seven in other cities. Initially, this special mathematics education took 4 years (Grade 9-Grade 12), later it has been expanded to 6 years (Grade 7 -Grade 12). Nowadays the two forms of training coexist. Sudents have 6 to 8 mathematics lessons per week, usually with two mathematics teachers per class. In our practice the lessons are divided equally between two teachers, one of them teaches mainly geometry, while the other teaches mainly algebra.

The aim of the introduction of the special mathematics program for highly talented students was to reform the contemporary Hungarian mathematics education at the end of the 50's of the last century. On the one hand, they tried to prepare a well-constructed, high quality mathematics curriculum, on the other hand, they formulated the principle developed by the team of János Surányi, that students should be taught to think independently. They interrupted the tradition that the teacher has to transfer the knowledge simply, instead, they preferred the constructivist method and encouraged students' active learning.

The curriculum of the special mathematics program in some topics goes far beyond the requirements of the compulsory final exam at the end of the 12th Grade. It also contains several components that are transition between high school and university curricula (e.g. complex numbers, matrices, Euler-Fermattheorem). It is important to emphasize that the main goal is not to prepare students for different math competitions, nevertheless the vast majority of participants of International Mathematical Olympiads will come from this educational system.

In Hungary, the purpose of the compulsory education is to furnish students with a useful set of knowledge that they can use succesfully in their life. At the end of the secondary education, the aim of the final exam is to show the students how deeply they acquired this set of knowledge, the modules of the educational program. Students can choose from two types of exam, they can take an intermediate or advanced level exam. Examining the exam tasks in mathematics

\footnotetext{
${ }^{1}$ The first class of major in mathematics was started at the "Fővárosi Fazekas Mihály" Primary and Secondary School (now called "Budapesti Fazekas Mihály" Primary School and Grammar School)
} 
concerning the van Hiele levels, we can recognize mid-level tasks' solutions require up to 3 van Hiele levels, because they do no need for proof. ${ }^{2}$ Students taking the advanced level final exam often have tasks in which they have to prove claims independently. That is to say, students taking the intermediate-level final exam possess van Hiele Level 3, while those who take the advanced level final exam, have van Hiele Level 4.

\section{Research question}

We conducted a longitudinal study to obtain information about geometrical thinking of talented high school students and formulated two research questions: How does the geometric thinking of the students participating in special mathematics program develop? What features do they show concerning the van Hiele levels?

\section{Research methodology}

During the survey, we used Zalman Usiskin's article (Usiskin Z., 1982), which has been widespread and has been used by many researchers earlier (Haviger \& Vojkůvková, 2013; Grigoriadu, 2012; Watson, 2012). The test in this article consists of 25 multiple choice tasks, with 5-5 tasks measuring each of the van Hiele levels. ${ }^{3}$ In accordance with the theory, a student achieves a certain van Hiele level if he/she meets the criteria for that level and all the levels below it.

Students did the test on paper, the working time was 35 minutes. They worked anonymously and provided an individual ID on the worksheets.

At the beginning of the longitudinal study, in June 2015, we measured the van Hiele level of 5 groups of students participating in the special mathematics program, who learnt in different grades of a grammar school and in different forms of training (Table 1).

\footnotetext{
${ }^{2}$ The tasks of final exam can be found on the page: https://www.oktatas.hu/kozneveles/ erettsegi/feladatsorok_vizsgatargyankent/! DARI_ErettsegiFeladatsorok/oh.php?id= erett_ut_reszlet

${ }^{3}$ We asked Usiskin for permission to use the test, which was translated into Hungarian by the authors.
} 
Ákos Győry and Eszter Kónya

\begin{tabular}{|l|c|c|}
\hline & 6-form education (Grade 7-12) & 4-form education (Grade 9-12) \\
\hline Grade 8 & Group A (12 students) & - \\
\hline Grade 9 & Group B (12 students) & Group D (15 students) \\
\hline Grade 10 & Group C (10 students) & Group E (14 students) \\
\hline
\end{tabular}

Table 1

We made a total of five measurements in Groups A and B at the following times: June 2015, September 2015, June 2016, September 2016, December 2016, while we measured the other groups twice, in June and September 2015. (It should be noted that in Hungary the school year begins on September 1 and ends in the first half of June.) For a better overview, let's see the measurement process on a time scale (Figure 1):

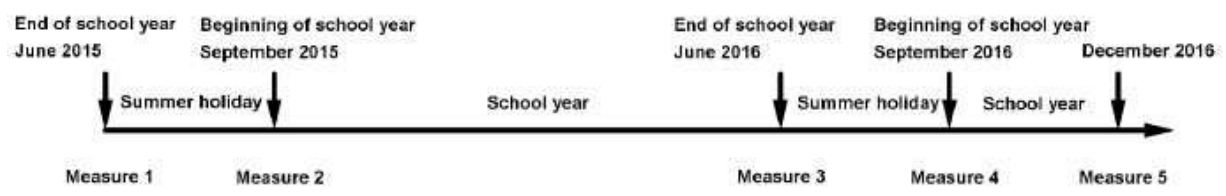

Figure 1

We considered the results obtained in two ways. On the one hand, we calculated the mean of the individual van Hiele levels within the group and examined the change of this mean. On the other hand, we analyzed the individual results.

Since the measurement of Level 5 is questioned by several researchers, we have also made the calculations even if Level 5 is omitted.

As we performed more than two measurements, we thought - and Professor Usiskin also con-firmed us - that the original test could not be used in unchanged form later (as students might recognize tasks or even remember their earlier answers). That is why we have prepared a new test. This test has already been constructed by the authors similarly to the Usiskin's one.

\section{The modified test}

The modified test was constructed in a way, that the structure and nature of the Usiskin's test were preserved, namely

- the test consisted of 25 multiple choice tasks; 
- each level was measured by 5 tasks;

- the content and the structure of the tasks were also similar to the original ones.

In order to illustrate the modified test we show parallel tasks from the original and from the modified test (Figure 2-5).

The original Task 5 (Level 1):

Which of these are parallelograms?
(A) J only
(B) L only
(C) J and M only
(D) None of these are parallelograms.
(E) All are parallelograms.

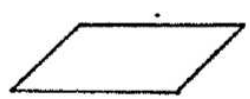

I
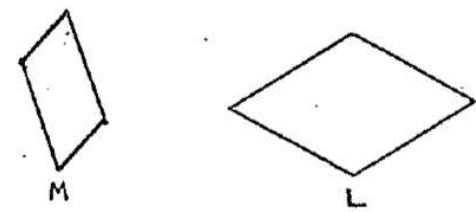

Figure 2

The new Task 5 (Level 1):

Which of these are trapezoids?
a. All of them are trapezoids.
b. $A$ and $C$ only.
c. $A, B$ and $C$ only.
d. $C$ only.
e. None of a.-d. is correct.

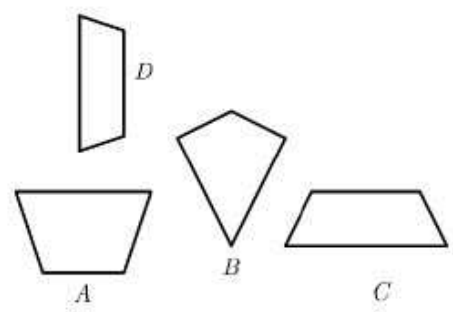

Figure 3 
The original Task 7 (Level 2):

In a rectangle GHJK, $\overline{\mathrm{GJ}}$ and $\overline{\mathrm{HK}}$ are the diagonals. Which of a.-d. is not true in every rectangle?

(A) There are four right angles.

(B) There are four sides.

(C) The diagonals have the same length.

(D) The opposite sides have the same length.

(E) All of (A)-(D) are true in every rectangle.

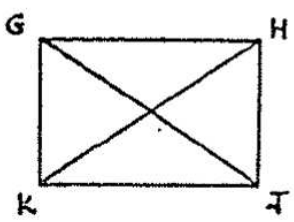

Figure 4

The new Task 7 (Level 2):

Let's consider an arbitrary $A B D C$ parallelogram (see figure). Which of a.-d. is not true?

a. Diagonals bisect each other.

b. In each case, $A B C D$ has point symmetry.

c. Opposite sides are parallel.

d. $C A B \Varangle$ and $A C D \Varangle$ are congruent.

e. All of a.-d. is true.

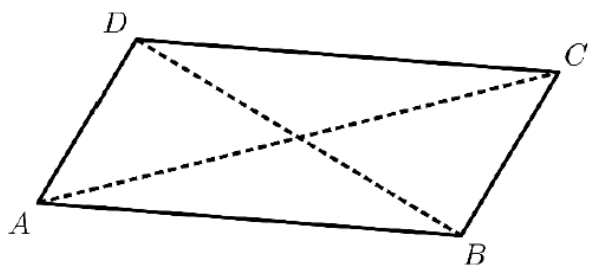

Figure 5

Here we note that there are no trapeziods in the original test, but they have a high priority in Hungarian mathematics education, so we often used them. The new test contains more geometric concepts than the original, so the working time was increased from 35 minutes to 40 minutes.

\section{Results}

In the tables below, the groups participating in the four class education will be $\mathrm{F}$, and the par-ticipants in the six class education will be marked with $\mathrm{S}$. The tests were originally written for more than the number of people listed, but due to 
the longitudinal examination, we only considered the achievement of the students who wrote each test.

It is important to emphasize that our research is mainly qualitative, the consequences derived from the obtained data represent the authors' point of view. However, the obtained mean values confirm the results. It would be a good idea to carry out measurements on a bigger population of students in order to evaluate the given data quantitatively by statistical means.

\section{Measures 1-2}

The first measurement was carried out at the end of the examined school year, while the second one at the beginning of the second investigated school year.

The results of the first two measurements are summarized in Table 2. In order to compare the achievement of the students before and after the summer holiday, we only show those students from the groups who completed both of the tests.

It is usually to look at a change of geometric understanding in one school year, but we were wondering if this was altered if so, during the summer holiday. This is shown in the last column of the table.

\begin{tabular}{|c|c|c|c|c|c|c|}
\hline Group & Grade & Duration of education & Number & June 2015 & September 2015 & Change \\
\hline $\mathrm{A}$ & $8 \rightarrow 9$ & 6 years & 12 & 2.75 & 4.17 & +1.42 \\
\hline $\mathrm{B}$ & $9 \rightarrow 10$ & 6 years & 12 & 4.25 & 3.58 & -0.67 \\
\hline $\mathrm{C}$ & $10 \rightarrow 11$ & 6 years & 10 & 4.50 & 4.60 & +0.10 \\
\hline $\mathrm{D}$ & $9 \rightarrow 10$ & 4 years & 15 & 3.80 & 3.53 & -0.27 \\
\hline $\mathrm{E}$ & $10 \rightarrow 11$ & 4 years & 14 & 4.00 & 4.57 & +0.57 \\
\hline
\end{tabular}

Table 2

It is clear from the table, that

- the mean of van Hiele levels of students participating in both 4- and 6-yeareducational formats increased;

- the mean of van Hiele level of students participating in a 6-year educational format is higher than the mean of those who are in a 4-year format;

- there are two groups whose van Hiele level's mean has increased clearly during the summer holiday (Group A and Group E), there are two groups whose mean has decreased (Group B and Group D), and there is a group whose mean has broadly stagnated (Group C). 
Two groups (Group A and Group B) studying in the same educational format showed a very large and counterproductive change. Group A showed a huge improvement, while B showed a lot of weaknesses. We had assumed several reasons as a possible explanation, so we had to carry out a new measurement one year later to support or refute them. These measurements were performed at the end of the second investigated school year (2015/2016), in June 2016, and at the beginning of the following school year (2016/2017) in September 2016.

\section{Measure 3-4}

\begin{tabular}{|c|c|c|c|c|c|}
\hline Group & Grade & $\begin{array}{c}\text { Number of } \\
\text { participants }\end{array}$ & $\begin{array}{c}\text { The mean of the } \\
\text { van Hiele levels } \\
\text { in June 2016 }\end{array}$ & $\begin{array}{c}\text { The mean of the } \\
\text { van Hiele levels in } \\
\text { September 2016 }\end{array}$ & Change \\
\hline $\mathrm{A}$ & $9 \rightarrow 10$ & 12 & 2.67 & 3.08 & +0.41 \\
\hline $\mathrm{B}$ & $10 \rightarrow 11$ & 12 & 3.08 & 3.08 & 0.00 \\
\hline
\end{tabular}

Table 3

Here we obtained similar result for Group A to the result a year earlier, i.e. clearly progress, if not so much. Although the mean of Group B did not decrease as it did a year earlier, however, its behavior was different from Group A as they had stagnated.

We can also notice that the second test both times was less successful than the original one. There are several explanations for this fact. On the one hand, in the second test there were statements concerning more geometric concepts, than in the first one (e.g. deltoids, trapezoids). On the other hand, in the Usiskin's test there are some statements measuring Level 5 which our students have already learned, namely Task 22 and Task 23.

Task 22: To trisect an angle means to divide it into three parts of equal measure. In 1847, P. L. Wantzel proved that, in general, it is impossible to trisect angles using only a compass and an unmarked ruler. From his proof, what can you conclude?

(A) In general, it is impossible to bisect angles using only a compass and an unmarked ruler.

(B) In general, it is impossible to trisect angles using only a compass and a marked ruler. 
(C) In general, it is impossible to trisect angles using any drawing instruments.

(D) It is still possible that in the future someone may find a general way to trisect angles using only a compass and an unmarked ruler.

(E) No one will ever be able to find a general method for trisecting angles using only a compass and an unmarked ruler.

Task 23: There is a geometry invented by a mathematician $J$ in which the following is true: The sum of the measures of the angles of a triangle is less than $180^{\circ}$. Which is correct?

(A) $J$ made a mistake in measuring the angles of the triangle.

(B) $J$ made a mistake in logical reasoning.

(C) J has a wrong idea of what is meant by "true".

(D) $J$ started with different assumptions from those in the usual geometry.

(E) None of (A)-(D) is correct.

With these problems students had already met during their studies, thanks to their high number of lessons per week and their special curriculum. Here the students simply remembered the correct answers without really analyzing the possible choices. This has unreasonably increased the mean of van Hiele level.

\section{Discussion}

We considered many possible explanations concerning the result and we have listed them below.

(1) Groups A and B have been taught by a different geometry teacher, which can significantly influence the development of the geometric understanding process. In our case, however, the same teacher taught both groups, so this factor can be omitted.

(2) Was Group A more motivated than B? Since the two groups were taught by the same geometry teacher and the test was written at the same time, we did not consider this to be a satisfactory explanation.

(3) During the summer holiday between the two tests, did Group A deal with more mathematics? This would be a very convincing explanation, but neither of the two groups received practical mathematical exercises in the summer holiday, and none of the group's students participated neither individually 
nor in groups in mathematics training, so this could not be the reason for the results.

(4) Is the development of the geometric understanding an age-specific feature? Group A in 2016 and Group B in 2015 were measured at the same age (Grade $9 \rightarrow 10$ ), and in the 9 th school year both groups learned by similar geometry curricula. The mean of the van Hiele levels of the first group improved during the summer holiday $(+0.41)$ while this value of the second group worsened $(-0.67)$. The difference between the values of change is remarkable, especially if we take into account that Group A wrote the more difficult modified test and Group B did the easier original test. As we mentioned before, the two groups in Grade 9 were taught by the same teacher, and the curricula were almost the same. So this explanation can be excluded.

(5) Does the school achievement in geometry determine the change of the van Hiele levels? To examine this, we collected all the students' geometry marks obtained during their 9th school year and analysed the change of each students' van Hiele level during the summer holiday (Table 4).

\begin{tabular}{|c|c|c|c|c|c|}
\hline \multirow[t]{2}{*}{ Group } & \multirow{2}{*}{$\begin{array}{c}\text { Mean of geometry marks } \\
\text { in Grade } 9\end{array}$} & \multirow{2}{*}{$\begin{array}{l}\text { The change of the } \\
\text { van Hiele levels' mean }\end{array}$} & \multicolumn{3}{|c|}{$\begin{array}{l}\text { Number of students, whose van Hiele } \\
\text { level during the summer holiday after } \\
\text { the } 9 \text { th Grade... }\end{array}$} \\
\hline & & & ... increased & ...stagnated & ... decreased \\
\hline $\mathrm{A}$ & 4.27 & +0.42 & 5 & 4 & 3 \\
\hline B & 4.07 & -0.67 & 0 & 7 & 5 \\
\hline
\end{tabular}

Table 4

It can be seen that Group A performed better (4.27) in the same grade than Group B (4.07). Since Group A is the one whose level increased during the summer holiday, the better geometry marks seems to be related to the increasing of the van Hiele level. To examine this, both groups were divided into 3-3 subgroups based on their annual geometry marks. There were 3 students in each subgroup. We investigated how the van Hiele level of each group changed in the 2014/2015 school year. We had obtained the following result (Table 5): 


\begin{tabular}{|c|c|c|c|}
\hline Group & Subgroups & Mean of geometry marks & Development \\
\hline \multirow{3}{*}{ A } & good achievement & 4.79 & 1 increased, 2 stagnated, 1 decreased \\
\cline { 2 - 4 } & medium achievement & 4.38 & 1 increased, 2 stagnated, 1 decreased \\
\cline { 2 - 4 } & weak achievement & 3.64 & 3 increased, 1 decreased \\
\hline \multirow{3}{*}{ B } & good achievement & 4.64 & 2 stagnated, 2 decreased \\
\cline { 2 - 4 } & medium achievement & 3.87 & 3 stagnated, 1 decreased \\
\cline { 2 - 4 } & weak achievement & 3.26 & 2 stagnated, 2 decreased \\
\hline
\end{tabular}

\section{Table 5}

It can be seen that the change was uniform, the subgroups performed similarly.

In order to confirm these findings better, we equalized the achievements of Group A and Group B in the following way: we noticed that if the best geometrymean student in Group A and the weakest student in Group B were excluded from the measurement, the mean of the geometry marks of the two groups would be quite the same (Table 6):

\begin{tabular}{|c|c|c|c|c|c|}
\hline \multirow[t]{2}{*}{ Group } & \multirow{2}{*}{$\begin{array}{c}\text { Mean of geometry marks } \\
\text { in Grade } 9\end{array}$} & \multirow{2}{*}{$\begin{array}{l}\text { The change of the } \\
\text { van Hiele levels' mean }\end{array}$} & \multicolumn{3}{|c|}{$\begin{array}{l}\text { Number of students, whose van Hiele } \\
\text { level during the summer holiday after } \\
\text { the } 9 \text { th Grade... }\end{array}$} \\
\hline & & & ... increased & ...stagnated & ... decreased \\
\hline A & 4.21 & +0.45 & 8 & 3 & 0 \\
\hline B & 4.19 & -0.73 & 0 & 7 & 4 \\
\hline
\end{tabular}

Table 6

Thus, we can say that in the case of two groups with roughly equal achievement in school geometry, not only the mean of students' van Hiele levels increased in Group A, but also the level of each student became higher or didn't change, while in Group B the situation was completely different. Based on these results, we believe that in this case the geometric achievement in the school cannot be considered as a decisive factor at the development of the students' geometric understanding during the summer holiday.

\section{The structure of the geometry syllabus as a decisive factor}

We have excluded many possible reasons beforehand, and we believe that finally there is only one factor which can explain the obtained results, namely the structure of the geometry syllabus in the school year. For this reason, we divided the geometry topics learned by each group into two parts:

(1) topics which develop students' geometric thinking primarily, like congruence or similarity of triangles; 
(2) topics which develop students' geometric thinking secondly (e.g. trigonometry or vectors' dot product), because in these branches the pure geometry occurs together with other areas of mathematics.

In addition to what is the ratio of the syllabus that improves or does not improve the geometric view, it is also important to examine what is the layout of the syllabi within the curriculum. Let us therefore give a percentage distribution of the syllabus in a time scale. The thick-framed rectangles represent the syllabus which improves the geometric view (Figure 6).

School year

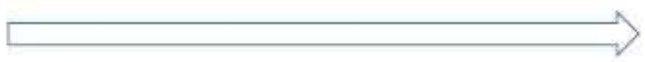

Summer change

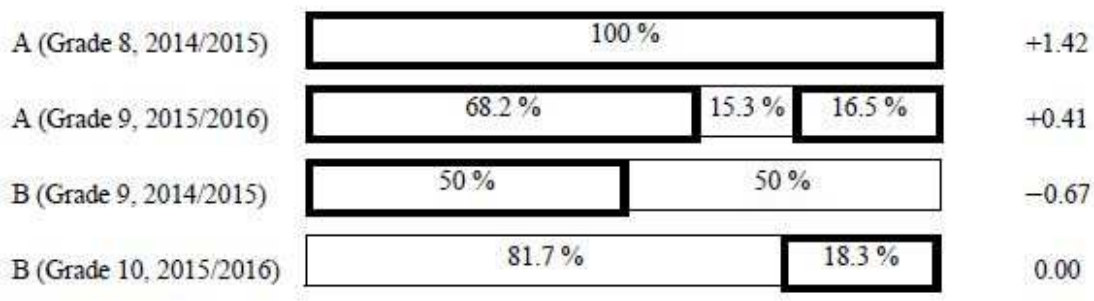

Figure 6

The percentages show the percentages relative to the annual number of lessons. For example, group A (Grade 9) first studied developer geometric topics in $68.2 \%$ of the annual number of lessons (cyclic quadrilateral, similarity of triangulars), then not developer geometric topics in $15.3 \%$ (trigonometry), and finally developer geometric topics in $16.5 \%$ (Ceva's theorem, Menelaus' theorem, Ptolemy's theorem, golden ratio).

Although the two groups participate in the same educational program, the structure of the syllabus, i.e. the order of the topics may differ, it is not strictly defined concerning one or two school years, it depends on the teacher's decision. It is therefore possible that in Grade 9 the two groups learned by different geometry syllabus, which is well reflected in the indicated ratios. I deliberately taught at the end of the school year in the two groups, because I wanted to know the consequences.

Let us consider the two groups per school year: 
- in the whole school year group A (Grade 8) learned a syllabus which improves the geometric viewpoint; in the summer after the school year they underwent remarkable development;

- most of the school year group A (Grade 9) learned a syllabus which improves the geometric viewpoint; in the summer after the school year they underwent significant development;

- in the first half of the school year the group B (Grade 9) learned a syllabus which improves the geometric viewpoint, but did not at all in the second half; in the summer after the school year they significantly worsened;

- group B (Grade 10) learned a syllabus which improves the geometric viewpoint only in the last part of the school year; in the summer after the school year the mean of their van Hiele levels did not change.

Based on the above-mentioned facts, our assumption is that the quality of the geometry syllabus and its distribution in the given school year are responsible for the change of the geometric viewpoint during the summer holidays. This hypothesis motivated us to restructure the syllabus, as mentioned earlier.

The summer holiday lasts roughly for 3 months. It was our idea to make a 5th measure just three months after the 4th measure to further support our hypothesis about the relationship between the quality of the learned syllabus and the change of the geometric viewpoint.

\section{Measure 5}

The results are shown in Table 7 .

\begin{tabular}{|c|c|c|c|c|c|}
\hline Group & Grade & $\begin{array}{c}\text { Number of } \\
\text { participants }\end{array}$ & $\begin{array}{c}\text { The mean of the } \\
\text { van Hiele levels in } \\
\text { September 2016 }\end{array}$ & $\begin{array}{c}\text { The mean of the } \\
\text { van Hiele levels in } \\
\text { December 2016 }\end{array}$ & Change \\
\hline A & 10 & 12 & 3.08 & 2.75 & -0.33 \\
\hline B & 11 & 12 & 3.08 & 3.00 & -0.08 \\
\hline
\end{tabular}

Table 7

Neither of the groups developed, group B slightly, and A significantly worsened. This is very remarkable, as group A, which showed development during two summer holidays without school, now that its students have gone to school for the same period as the summer holidays, has shown a decline. The cause of the decline could be found repeatedly in the syllabus: both groups during this time 
learned a syllabus that do not develop the geometric viewpoint (these are related to generalized trigonometry), which supports our assumption of the correlation between the changing of the geometric viewpoint and the quality of the learned curriculum.

\section{Results without Level 5}

We mentioned earlier that it is not yet clear whether the test is able to measure Level 5 so we did the calculations by leaving out Level 5 . The results are shown in Tables 8-10.

\begin{tabular}{|c|c|c|c|c|c|}
\hline Group & Grade & $\begin{array}{c}\text { Number of } \\
\text { participants }\end{array}$ & $\begin{array}{c}\text { The mean of the } \\
\text { van Hiele levels } \\
\text { in June 2015 }\end{array}$ & $\begin{array}{c}\text { The mean of } \\
\text { the van Hiele } \\
\text { levels in } \\
\text { September 2015 }\end{array}$ & $\begin{array}{c}\text { Change } \\
\text { (Change with } \\
\text { the 5th Level) }\end{array}$ \\
\hline $\mathrm{A}$ & $8 \rightarrow 9$ & 12 & 2.58 & 3.58 & $+1.00(+1.42)$ \\
\hline $\mathrm{B}$ & $9 \rightarrow 10$ & 12 & 3.67 & 3.25 & $-0.42(-0.67)$ \\
\hline
\end{tabular}

Table 8

\begin{tabular}{|c|c|c|c|c|c|}
\hline Group & Grade & $\begin{array}{c}\text { Number of } \\
\text { participants }\end{array}$ & $\begin{array}{c}\text { The mean of the } \\
\text { van Hiele levels } \\
\text { in June 2016 }\end{array}$ & $\begin{array}{c}\text { The mean of } \\
\text { the van Hiele } \\
\text { levels in } \\
\text { September 2016 }\end{array}$ & $\begin{array}{c}\text { Change } \\
\text { (Change with } \\
\text { the 5th Level) }\end{array}$ \\
\hline A & $9 \rightarrow 10$ & 12 & 2.42 & 2.92 & $+0.50(+0.41)$ \\
\hline B & $10 \rightarrow 11$ & 12 & 2.75 & 2.83 & $+0.08(0.00)$ \\
\hline
\end{tabular}

Table 9

\begin{tabular}{|c|c|c|c|c|c|}
\hline Group & Grade & $\begin{array}{c}\text { Number of } \\
\text { participants }\end{array}$ & $\begin{array}{c}\text { The mean of the } \\
\text { van Hiele levels in } \\
\text { September 2016 }\end{array}$ & $\begin{array}{c}\text { The mean of } \\
\text { the van Hiele } \\
\text { levels in } \\
\text { December 2016 }\end{array}$ & $\begin{array}{c}\text { Change } \\
\text { (Change with } \\
\text { the 5th Level) }\end{array}$ \\
\hline A & 10 & 12 & 2.92 & 2.58 & $-0.34(-0.33)$ \\
\hline B & 11 & 12 & 2.83 & 2.75 & $-0.08(-0.08)$ \\
\hline
\end{tabular}

Table 10

It can be seen that we got similar results just like before. That is the result of the measurements was not affected when Level 5 was taken into account. 


\section{Conclusions}

In the paper we examined the change of the geometric approach of students specialized in mathematics in the summer holiday. Based on the results of the measurements we believe that the development of geometric thinking is primarily influenced by the quality of the geometric syllabus and its distribution during the school year.

Students of the group who studied topics which improve geometric approach in the vast majority of the school years have developed significantly. In addition, we found a connection between the quantity of their development and the learned geometric curriculum in the last period of the school year.

We have also found that certain geometrical topics specifically hinder by the development of a geometric thinking. The group that showed huge progress during the summer holiday, while not dealing with mathematics at all, regressed in learning of geometrical curricula of the same duration, which are not developing.

\section{Acknowledgement}

We would like to thank Prof. Csaba Szabó for inspiring and helping us to start this research.

\section{References}

[1] M. Crowley, The van Hiele model of development of geometric thought, in: In Learning and Teaching Geometry, K-12, 1987 Yearbook of the National Council of Teachers of Mathematics, (Mary Montgomery Lindquist, ed.), National Council of Teachers of Mathematics, Reston, Va., 1987, 1-16.

[2] O. Grigoriadu, Reasoning in geometry - How first learning to appreciate the generality of arguments helps students come to grips with the notion of proof, Msc Thesis, University of Amsterdam, 2012.

[3] A. Gutierrez \& A. Jaime, On the assessment of the van Hiele levels of reasoning, Focus on Learning Problems in Mathematics 20, no. 2-3 (1998), 27-45.

[4] A Gutierrez, A. Jaime \& J. Fortuny, An alternative paradigm to evaluate the acquisition of the van Hiele levels, Journal for Research in Mathematics Education 22, no. 3 (1991), 237-251.

[5] E. Halat, Sex-related differences in the acquisition of the van Hiele levels and motivation in learning geometry, Asia Pacific Education Review 7, no. 2 (2006), 173-183. 
110 Ákos Győry \& Eszter Kónya : Development of high school students' geometric thinking

[6] E. Halat, Reform-based curriculum \& acquisition of the levels, Eurasia Journal of Mathematics, Science and Technology Education 3, no. 1 (2007), 41-49.

[7] J. Haviger \& I. Vojkůvková, The van Hiele Geometry Test at Czech Secondary School, in: WDS'13 Proceedings of Contributed Papers, Part I, 2013, 112-115.

[8] J. Haviger \& I. Vojkůvková, Procedia-Social and Behavioral Sciences 112, 2014, 977-981.

[9] E. Herendiné Kónya, The characterictics of the geometric thinking of teacher trainees (In Hungarian: A tanítójelöltek geometriai gondolkodásának jellegzetességei), Iskolakultúra 12 (2003), 51-61.

[10] M.M. Mason, The van Hiele Model of Geometric Understanding and Mathematically Talented Student, Journal for the Education of the Gifted 21, no. 1 (1997), $39-53$.

[11] J. Mayberry, The van Hiele levels of geometric thought in undergraduate preservice teachers, Journal for Research in Mathematics Education 14 (1983), 58-69.

[12] L. Surányi, "I have experienced few such a motivating atmosphere" The 50th anniversary of special mathematics education (In Hungarian: ,Kevés ilyen inspiráló légkört tapasztaltam" Ötvenéves a speciális matematika tagozat), Természet Világa 143, no. 6, June (2012).

[13] Z. Usiskin, Van Hiele Levels and Achievement in Secondary School Geometry, University of Chicago, 1982.

[14] C. Watson, A Comparison of van Hiele Levels and Final Exam Grades of Students at The University of Southern Mississippi, Honors Theses, Paper 88, 2012.

[15] E. Yetkin, Student difficulties in learning elementary mathematics, ERIC Clearinghouse for Science, Mathematics, and Environmental Education, DIGEST, EDO-SE-03-06 (2003).

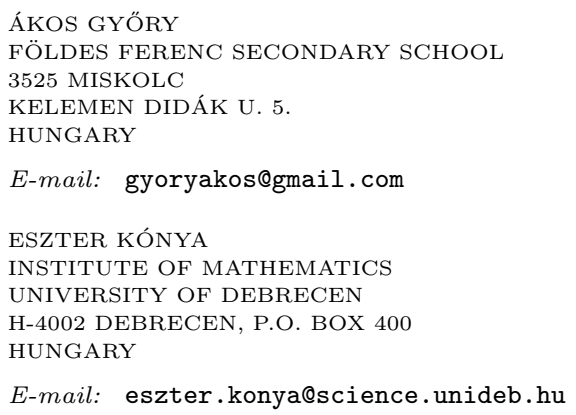

